\title{
Using UX research techniques to explore how Computing undergraduates understand and use library and student guidance services
}

\author{
Laura Woods \\ University of Huddersfield, UK \\ Richard Dockery \\ University of Huddersfield, UK \\ Alison Sharman \\ University of Huddersfield, UK
}

\begin{abstract}
This collaborative project, between the library and student guidance services at a mediumsized UK university, used qualitative User Experience (UX) techniques to explore Computing undergraduates' experiences of support services. The research found that most students struggled with academic skills, and felt they had lacked support in developing academic literacies. Students were often unaware of support services available from student guidance and the library. Many struggled to balance studying with work, commuting, or family life. Lack of time due to external commitments may be a barrier to accessing support services. This research project has suggested several avenues for future research, including a larger-scale study to investigate demographic categories such as mature students and overseas students, and an exploration of the needs of commuter students.
\end{abstract}

Key words: academic skills teaching; cross-team collaboration; support services; user experience.

\section{Introduction}

This study examines how Computing undergraduates experience support services, and how these can be better utilised to support students' development of academic literacies. The study was a collaboration between the library subject team and the student guidance 
team at the University of Huddersfield, a mid-sized, post-1992 University in the North of England.

The study focused on Computing students because previous research had found that these students showed disproportionately low use of the library (Collins and Stone, 2014). This is a concern, as library use correlates with both higher grades and higher retention (Abrams and Jernigan, 1984; Soria et al., 2013; Stone and Ramsden, 2013; Collins and Stone, 2014).

The cross-team approach allowed us to explore how both the library (which provides information literacy support across the whole university) and student guidance (which provides study skills and personal development support to students in the School of Computing and Engineering (SCE)) were seen by students. Study skills and information literacy are closely linked so exploring both together allowed us to identify where further collaboration could be useful.

This research used User Experience (UX) techniques to gain a holistic view of students' experiences of support services, how they approached their assignments, and what library resources they used to support their work. The aim was to understand how students understood and engaged with support services, and what barriers might prevent them accessing support services as needed.

Historically, user research in libraries and support services has mainly consisted of quantitative methods such as measuring usage statistics of library resources, or mixed methods such as questionnaires and surveys (Priestner and Borg, 2016, p. 3). These methods are useful for giving a large-scale picture of what the majority of library users are doing, but they provide no context on the quality of the user experience, or why users make certain decisions that may seem counter-intuitive.

By contrast, UX research techniques are well-suited to gaining in-depth insight into small groups of users. UX is increasingly used in libraries to explore topics of concern to library users and non-users (Ramsden, 2016). The techniques are mainly derived from ethnography and are subject-led: rather than having an interviewer with set questions, questions are drawn from the interviewee's initial thoughts on the topic. They allow the 
researcher to gain a more accurate picture of how users experience libraries: a key concern in higher education where the 'student experience' is increasingly central to how university services are evaluated (Priestner and Borg, 2016, p. 2).

This research used several UX activities in combination. These techniques are described in full in the Methodology section.

\section{Literature review}

There is a recognised need for universities to support students in developing study skills, particularly among post-1992 universities who often have higher numbers of students from 'non-traditional' backgrounds (Wingate, 2006). This is key to improving both academic performance and retention (Mezick, 2015). Feeling unprepared for the challenges of academic study and unsupported in developing the skills needed are common reasons for students to withdraw from their courses (Jones, 2008).

New students often feel uncertain about what is expected of them at university. In a study of first-year social work students at a UK university, Goldingay et al. (2014, p. 46) found that students 'stated they felt like they had to "learn" these inherent assumptions during their initial weeks at university, while simultaneously learning course material and navigation of the institution as a whole'. New students may also be reluctant to use their university library due to a phenomenon referred to as 'library anxiety' (Jiao et al., 1996). This may be more common where students are unused to using libraries, unsure of what services are available, and have not had training or advice from library staff (McPherson, 2015). Uncertainty about 'knowing the rules' of the university environment in general is another factor that may lead students to withdraw from their studies (Crosling et al., 2009).

Study skills support, such as that provided by the library and other support services, can go some way towards addressing these anxieties. A study skills course at a US university was found to increase 'academic self-efficacy' (i.e. confidence and self-motivation in academic ability) among students identified as 'academically underprepared' (Wernersbach et al., 2014). There is also evidence that attending study skills classes and 
seeking help from dedicated study skills tutors or librarians is associated with higher grades (Abrams and Jernigan, 1984; Beisler and Medaille, 2016).

However, the common 'bolt-on' approach to study skills, where support is offered outside of timetabled classes and unconnected to module outcomes and assessments, is less effective in addressing student anxieties and increasing attainment (Wingate, 2006). Students who are in the most need of study skills support, such as those with low confidence and low skills in academic reading and writing, are the least likely to seek out such help (Dodgson and Bolam, 2002). This may be for several reasons: students may see having to seek help as a threat to their self-esteem (Karabenick and Knapp, 1991), may be unaware of what support is available and how to seek it out, or may simply struggle to fit additional support sessions or appointments into their already busy schedules (Goldingay et al., 2014). Where students do seek help, they are more likely to do so from 'unthreatening' sources such as their friends and family, and tend to do so towards the end of their assignment-writing process, despite recognising that the research and information-gathering stages at the start of an assignment presented the most challenges (Beisler and Medaille, 2016).

Another factor impacting the take-up of support services at universities is the increase in commuter students, i.e. those who live locally to the university and commute in, rather than living in university accommodation. The demographics and working patterns of university students have changed over the last ten years. According to Thomas and Jones (2017) there is an increasing trend for students to live at home and travel. In 2014/15, 55.8\% of students in English universities travelled to learn (Donnelly and Gamsu, 2018). Students who commute into university, or who are juggling studying with work, family or caring responsibilities, are less likely to engage with support services outside of timetabled classes (Thomas and Jones, 2017).

This literature shows the importance of targeted and structured study skills support for students. There is little published research on collaborative efforts between the library and other support departments. The current study aims to fill this gap by exploring how students view study skills and support services as part of their overall experience of studying and university life. 


\section{Methodology}

\section{UX techniques}

Library staff at the university had previously used UX techniques in related research with international students, also identified as low library users (Jensen et al., 2019). The objectives for this research were similar enough that it was thought the same UX methods would be suitable.

The techniques, the first two adapted from Asher and Miller (2011), were:

1. Retrospective process interviews

2. Cognitive mapping

3. Card-sorting.

These UX techniques are what Asher and Miller (2011) term as applied ethnographic research methods, which allow '... the researcher to tell a group's story from the point of view of participants by deeply examining the context in which activities occur'. We used multiple methods to give us a more complete picture as to how students are using support services.

\section{Retrospective process interviews}

Students were asked to sequentially note down the different stages they go through to complete a project or assignment, from first receiving the brief, up to submitting the completed assignment. They explained their drawings to the interviewer who asked relevant questions or invited them to elaborate on specific points.

This method is participant-led, meaning the student directs the conversation. It enabled the researchers to explore how students tackled their assignments, how and from whom they sought help if required, and any hindrances that impeded their study.

\section{Cognitive mapping}

Cognitive mapping was used to find out where students go to learn or study. Students were given an A3 sheet of paper and instructed to draw a map of their preferred study spaces, for six minutes. They were asked to change the colour of their pen every two 
minutes, in a set order. This enabled the researcher to identify which parts of the drawing were completed first, as this is likely to indicate which spaces the participants considered most important.

The researcher then asked open-ended questions, prompted by the drawings. As with the retrospective process interview, this method is participant-led. It enabled the researchers to explore where and how the students preferred to study, and identify any barriers to using university-provided spaces such as the Library.

\section{Card-sorting}

Students were given a set of cards with the names of a mixture of free, web-based sources, and scholarly sources printed on them (see Table 1).

The students were asked to sort these into three piles: resources they used frequently, those they sometimes used and those they never used. The researcher then asked the student to talk through why they had placed certain cards in certain piles.

Table 1. Resources from card-sorting exercise.

\begin{tabular}{|l|l|l|}
\hline $\begin{array}{l}\text { General library } \\
\text { resources }\end{array}$ & $\begin{array}{l}\text { Subject-specific } \\
\text { resources }\end{array}$ & $\begin{array}{l}\text { Free web-based } \\
\text { resources }\end{array}$ \\
\hline $\begin{array}{l}\text { Summon (the library } \\
\text { catalogue and discovery } \\
\text { tool) }\end{array}$ & Lynda.com & Google \\
\hline Books & Digital Tutors & Google Scholar \\
\hline e-books & Eat3D & YouTube \\
\hline Journals & 3D Motive & Wikipedia \\
\hline Mintel reports & $\begin{array}{l}\text { GDC Vault (GDC: Games } \\
\text { Developers Conference) }\end{array}$ & \\
\hline Lecture notes & Total Training & \\
\hline
\end{tabular}




\begin{tabular}{|c|c|}
\hline Lecture capture & $\begin{array}{l}\text { IEEE Xplore (IEEE: } \\
\text { Institute of Electrical and } \\
\text { Electronics Engineers) }\end{array}$ \\
\hline & $\begin{array}{l}\text { ACM Digital Library } \\
\text { (ACM: Association for } \\
\text { Computing Machinery) }\end{array}$ \\
\hline
\end{tabular}

\section{Recruitment of volunteers}

Participants were recruited via SCE lecturers who asked for volunteers in class, and passed their details on to the researchers. Each student was offered a £10 voucher as an incentive.

Three students from each year of undergraduate study were recruited (years 1, 2 and 4: the courses include a placement year, so year 3 students are not on campus). This allowed the researchers to compare the experiences of students as they transitioned through their study. Their responses have been anonymised: throughout this paper they will be referred to by numerical codes. Volunteers were recruited from courses in Computing and Information Systems, Computing in Business, Computer Games Programming, and Information and Communication.

Ethical clearance for the research was granted by the School. Each student at the beginning of the research was told the reasons for conducting the research, informed that they could withdraw from the research, and told how their information would be recorded, stored and analysed.

All interviews were recorded with the consent of the student. Drawings and notes made by the students were retained and photographs were taken of the card-sorting results.

When discussing the findings of this research, it is important to bear in mind that these are drawn from a very small pool of subjects. We cannot state that these issues would be common to all students on these courses, based on a sample group of nine, self-selected volunteers. 
It was noticeable in the interviews that all the students were aiming for (and often achieving) high grades. It is possible that motivated and high-achieving students were more likely to volunteer for this research project, and therefore they may not have been representative of the full range of students enrolled on Computing courses.

After interviewing the nine students and beginning analysis of their interviews, it was decided to conduct follow-up interviews with four members of teaching staff from the same courses. This was to gain the academics' perspective on some of the themes raised in the student interviews, and to clarify academic expectations of students.

The academic staff were also asked to conduct the card sorting exercises: once to identify the sources they used for their own research, and then to identify what they expected students to use.

Responses from academic staff have been anonymised, and will be referred to by letters $A, B, C$ and $D$.

\section{Findings}

\section{Academic skills}

Most students reported struggling with academic skills, especially independent study and academic reading and writing. They found the standards higher than they had experienced in further education (FE), with more emphasis on self-directed study:

...it is a lot more independent. Like, you do everything yourself... They make you think a lot more than what they did at 6 th form...I'm still kind of adjusting. But l'm getting used to it. (Student 5, yr1)

The lack of regular structure to the academic day vexed some students who struggled to adapt to gaps in their timetable. Some comments indicated understanding that "gaps" in timetables were in fact intended for independent learning, rather than being free time:

It's one thing that is quite irritating for me now, for example, my Mondays, I've got a lecture at 10-11, then a 2 hour gap, then a lecture then another 
2 hour gap. So by the time it would take me to walk home, l'd need to be back to uni again...But I find ways of using up that time and studying. (Student 4, yr4)

Staff noticed differences in students' abilities and approaches to academic work based on what kind of prior educational experience they had:

students who have attended ...colleges with a programme that is a lot closer to a university's programme, they are very well prepared, in terms of know how to use sometimes Google Scholar, know how to do referencing...so that gives them a good starting point but that's very rare at least at this university in our department. (Staff D)

Some students found some of the course content was already familiar from their time in FE, but the style of assignments was more academic than they had experienced previously. Some final year students struggled with structuring essays as they had only had to write technical reports in their first and second years:

But an essay is different... and I was like, I actually don't know what to do...I mean I got there, I didn't get the best grade. (Student 3, yr4)

The research showed how the students' study practices had changed as they progressed through university, as they developed an appreciation of the importance of research and factored it into their assignment preparation. They also used more academic sources rather than relying on Google:

In 1st year, I'm not gonna lie, it was more Google... And now it's more academic, like I have to look for journals, books, all that kind of stuff... now I start researching way before I even started it in first year. (Student $3, \mathrm{yr} 4)$

It is clear from the comments that students' academic practices improve as they develop confidence and experience throughout their university career. There is a need for 
structured support throughout this time: first year students felt lost and confused by academic requirements, while final year students had developed their own coping techniques through trial and error. It is worth remembering that the final year students interviewed for this study were high achievers. It is possible that less capable and motivated students may not have developed successful academic strategies and skills without adequate support.

\section{Support services}

Students were either unaware of support services (including student guidance and the library) or reluctant to use them. Most preferred to ask their friends for advice, either faceto-face or online:

When working in a group, done most of the work in the classroom, anything we've needed to do outside we've got a group on Facebook so we'll just talk about it. (Student 2, yr1)

Some indicated they had struggled alone rather than ask for help, even when they identified that help could have been useful:

If I have been feeling stressed, I've just really put it upon myself to say I can do it. Like I didn't want to ask for an extension, so I just made myself do the work to not need one. (Student 4, yr4)

The student guidance service was underused and its purpose frequently misunderstood. It was often confused with the Student Support Office, which fulfils a purely administrative role.

Students were frequently unaware of what student guidance could do for them and wished they had used them when they found out. Those students who had used the service were positive about the help they had received: 
[After being offered support with a managed work plan by the Student Guidance Adviser] I never knew that, thank you sir. I wish I would have come to see you sooner. (Student 8, yr1)

The library was similarly underused. Several students opted to access materials electronically as opposed to visiting the library itself and therefore were unlikely to request help from librarians. This was a common theme throughout the year groups. Notably final year students were more likely to visit the library, access physical resources, and seek help from library staff.

Some students felt it would have been beneficial to have had more library input in their degree. They wanted the librarians to come into classes on a regular basis:

So I think what probably might have been more beneficial is if the library kept coming to us, maybe throughout first year, throughout second year, you know constant reminders like you are here, we can help you, sort of thing. (Student 1, yr4)

One student expressed disappointment that they had not had library help sessions on his second year module, especially as he was unsure about the use of secondary sources. He felt it might have helped all of the students:

[Interviewer: We used to go into the session to help the students]. Did you do that this year? It could have helped. You could have saved everyone. (Student 9, yr2)

The fact that students were unaware of the support available to them through the student guidance and the library, despite both services being prominently featured in first year inductions, indicates that support services need to be a continual presence. Regular visits from librarians and student guidance throughout first and second year timetables would be beneficial. 
Woods, Dockery and

\section{Use of scholarly sources}

Most students preferred to use web-based sources (such as Google and YouTube) and their lecture notes rather than scholarly sources. Free sources such as Google and YouTube were heavily used by first and second year students. Final year students were slightly more likely to use scholarly sources. See Figure 1 and Figure 2 for a breakdown of resource use by frequency and year of study.

\section{Figure 1. Resource use by all students.}

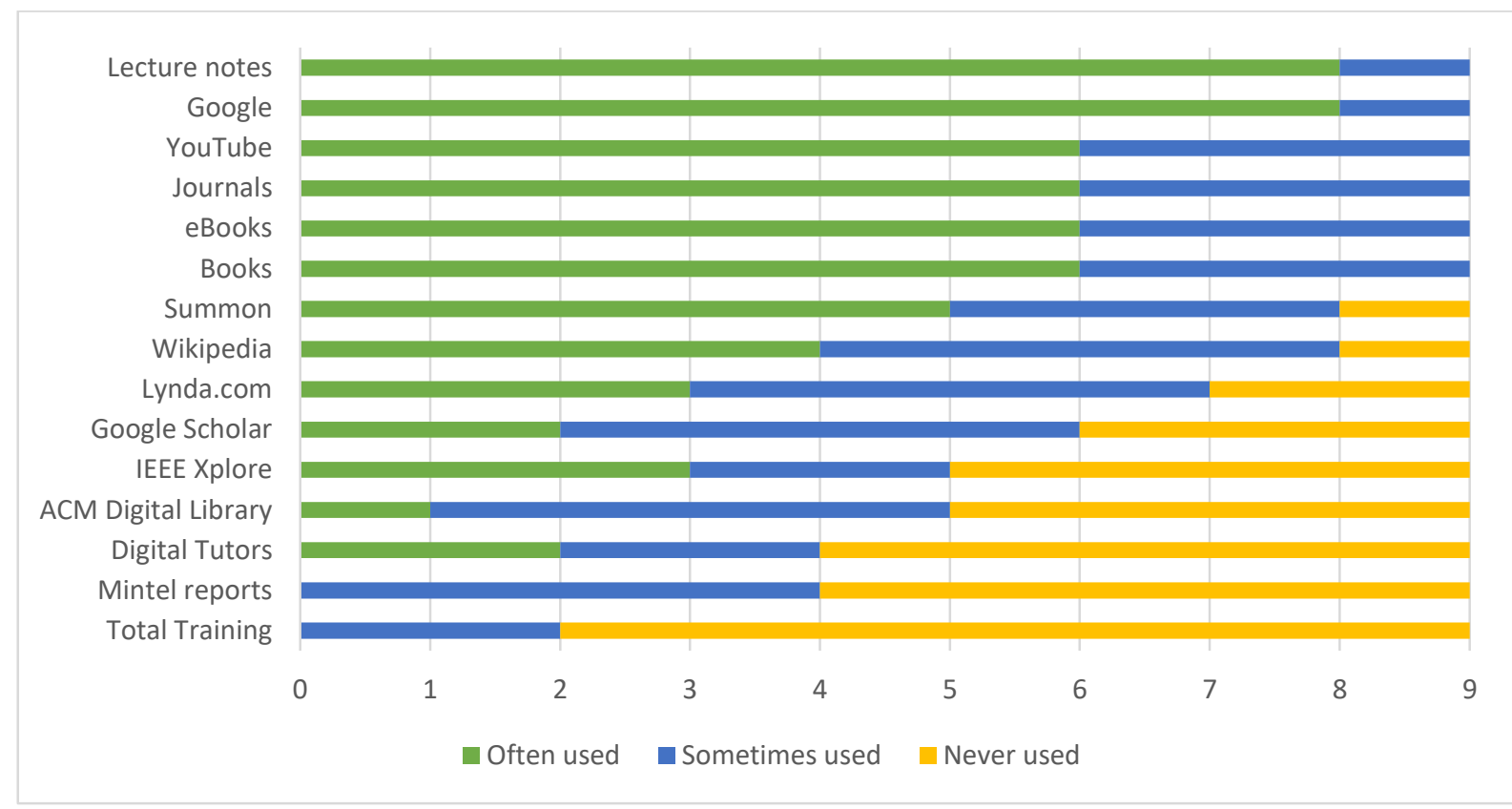


Figure 2. "Often” used resources compared across years.

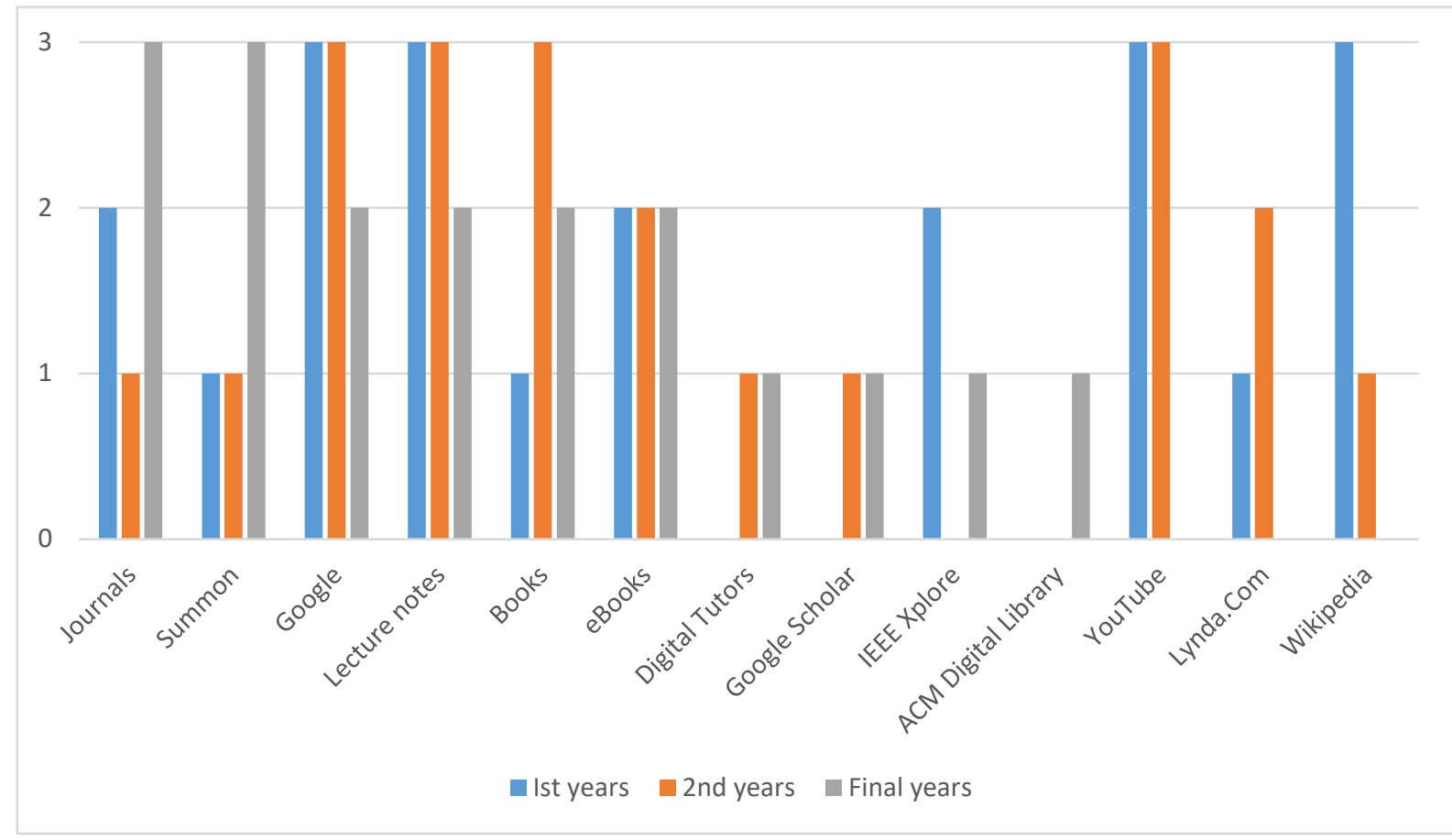

Web search engines (mainly Google) were heavily used by all students. Some comments indicated that the students were using such sources in an appropriate way either as a starting point for research, or to find non-scholarly material:

Google is important because when l've gone through an assignment and picked out key words, if I don't know what a key word is, before I start researching it, it makes sense for me to go and see if I can get a basic definition of what it is. (Student 1, yr4)

However, the staff interviewed believed their students were over-reliant on Google:

They're not going to read a book, they're not even going to look at a book, it's Google and whatever's on the top first page of Google is what they'll look at. (Staff C)

This could indicate that either a) the staff overestimate how much their students use web search, or b) the students downplayed their use of Google. This requires further research. 
YouTube was used by all students, mainly for programming and coding tutorials. The staff indicated that they saw students using YouTube frequently, although one expressed concern that they were missing out on better quality resources available elsewhere:

I would say YouTube must be $90 \%$ of their usage I think... In fact so many of them will come and say 'I couldn't find a tutorial on YouTube'. Have you looked anywhere else? (Staff $A$ )

Most students were aware of video training database Lynda.com, but rarely used it despite recommendations from lecturers. YouTube was seen as more 'accessible', possibly referring to the style and language used, but could also indicate that the requirement to log in to subscription sources such as Lynda.com is a barrier to use.

Students at all levels reported using some scholarly sources, but to differing levels. All three final year students used academic journals. One commented that they had increased their use of journals since their first year, having realised that their work required more academic sources:

In $1^{\text {st }}$ year, I'm not gonna lie, it was more Google ...I think now I look more journals and books because it's more academic isn't it. (Student 3, yr4)

Only two of the first years said that they had used journal articles, and this was specifically because they had been required to by a lecturer. The implication was that they probably would not have used them otherwise.

Where library sources were used, all students preferred those that were available online. Some students mentioned preferring e-books over print books because of the convenience of accessing them from home. This was particularly important for students who commuted into the university or were fitting studying around other commitments.

Free online resources are preferred, most likely because students are already familiar with them and see them as easier to use. This could be related to academic confidence: a free web page is likely to be written in simpler language and be easier to understand than a 
scholarly journal article. It could also be that the requirement to log in to library databases is seen as a barrier to use.

\section{Work/life balance}

Balancing studying with work, commuting, or family life was a consistent theme. It is possible that a lack of time is a barrier to accessing optional (i.e. non-timetabled) support services. Student 8 explicitly stated that the reason they did not access library support was because they did not have time to.

External commitments undoubtedly have an impact on independent study. For example, Student 2 has no weekend commitments and is therefore able to stay in the library for long hours. By contrast, Student 1 commutes into university during the week and then works at the weekend:

I'm restricted because I commute in, my last direct train is 18.45 so I have to be done by that time else I won't get home. (Student 1, yr4)

Three of the students, two of whom were mature students with children, noted that they had to study mostly at home rather than in the library due to the restrictions on their available time:

Mainly I study at home because basically l'm working and the family. As soon as I finish a session I go to pick up the kids from the school, take them home and have the tea. (Student 8, yr1)

Two participants spoke about how their employment affected their study patterns:

I work weekends. I'm gonna quit my job soon to focus on work [studying], but I work 8 hours a day Saturday and Sunday, so there's no chance for me to do any work. (Student 1, yr4) 
Two mature students mentioned how they balance their studying with caring for their children. One was broadly positive about the support they had received from the university, although the other had found difficulty with getting their timetable rearranged to accommodate their caring responsibilities:

Even getting here for nine thirty today was difficult with the dropping my child at school for ten to nine and then getting through the rush hour here. (Student 8, yr1)

Two students spoke about how their commuting to university dictated how and where they would work. Another student said they are more productive when working in the morning, but are unable to take advantage of this due to their long bus journey.

The university has a high proportion of both mature students and commuter students (and many who are both). It is therefore important to consider how external commitments such as work, family and commuting time impact on the student experience. These interviews show evidence that mature and commuter students, and those who work while studying, experience barriers to accessing support services.

This could be partly because support services are largely structured on the assumption that students will be in university during the working day. Flexible, out-of-hours and remote support services could all improve access for students who may not be able to stay in university outside of timetabled hours.

\section{Recommendations}

The research highlighted several areas for student guidance and library services to consider for enhancing the student experience. These fall under four overarching recommendations:

1. Regular visits from the library and student guidance

2. Support for peer mentoring

3. Promotion of academic sources 
4. Consideration of commuter and mature students when timetabling

\section{Regular visits from the library and student guidance}

Numerous comments about not being aware of the services available from the library and student guidance indicate a need for a continual presence of support staff, beyond the initial presentations to first year students in the first week of term. In addition, many comments regarding the challenges of literature-based written assignments suggest that additional support would be welcome.

Regular visits and updates from both the library and student guidance throughout students' academic careers could help to address points highlighted in the interviews. These, at a minimum, should include:

a) Regular and timely communication to all year groups of the services offered by student guidance and the library.

b) Development of a suite of workshops on independent learning, academic writing, and approaches to study.

c) Hold library drop-in advice sessions in the SCE buildings, to encourage students who may not have the time to walk across campus between classes to seek help or access optional workshops held in the library.

d) Offer research skills classes for second year students, who reported forgetting information given to them in their first year about the library and student guidance. At present the majority of research skills classes delivered by the librarians and student guidance are timetabled for first years and final years only.

\section{Support for peer mentoring}

By far the most frequent support accessed by students of all year groups was from their friends and peers. Most were unlikely to access 'official' channels of support, partly due to lack of awareness of support services.

Given that most second and final year students indicated that their own academic habits had improved vastly since their first year, this indicates an opportunity for peer mentoring. 
For example, final year students could provide advice to first years about things they wish they had known in their first year. In a more formal way, first year students could be partnered with volunteers from the second or final year of the course. The more experienced students could provide advice on developing their academic skills, and signpost to other support services as needed.

\section{Promotion of academic sources}

Students were more likely to make use of library resources if their lecturers specifically required them to, or in later years of the course when they had developed a greater understanding of the information landscape of their field of study.

Academic staff indicated that they did recommend library resources to their students, but observed that students frequently preferred to use 'easier' resources, for example choosing YouTube over Lynda.com.

Reading lists were considered helpful by first years in particular, but could also be useful for later year students who were uncertain where to begin on a topic. Actively using a reading list (for example, referring to it in teaching and in assignment marking rubrics) sets the expectation that students should be engaging with academic materials.

\section{Consider commuter and mature students when timetabling}

Given that approximately half of the university's student population commutes to study (University of Huddersfield, 2016), it is essential that the needs of commuter students are taken into account. Similarly, the number of comments regarding balancing studying with family, caring responsibilities, or employment, also indicate areas in which students may require further support.

As far as possible, the School should try to condense timetables to help students who commute or have busy family or working lives. Flexible timetabling has been recommended by the Sutton Trust as a way of supporting commuter students in particular (Donnelly and Gamsu, 2018). 
The library stays open $24 / 7$ for the majority of the academic year. This is appreciated by many students, particularly those who fit their studying around other commitments. However, 24/7 access carries the slight risk of promoting unhealthy studying habits, and contributing to stress levels. The library should continue to promote $24 / 7$ access as a way of studying on a flexible schedule, and should consider working with Disability and Wellbeing to encourage healthy studying habits.

\section{Conclusion}

This research has provided valuable insight into the studying habits of Computing undergraduates, and their perceptions of support services. Using participant-led ethnographic research techniques allowed us to explore their concerns in a holistic way, and provided responses that may not have surfaced in a researcher-led interview.

This research project has suggested several avenues for future research. It would be useful to explore how student experiences and support needs differ according to demographic, such as international students. It has not been possible to break down the current study by demographics, due to the small sample size. A larger-scale study would enable this, but would not necessarily use UX techniques as they are better suited to smaller groups of participants.

More research is needed into students' use of web sources and scholarly sources. Although the card-sorting exercise was useful to get an impression of the types of information sources students use, self-reporting may not give an accurate picture. Students may over- or under-estimate their use of certain sources, either from difficulty recalling their past research accurately, or reluctance to admit poor academic practice. Live-recording ethnographic methods such as research diaries, self-narration, or observation of students' use of library databases may help build a more accurate picture.

The issue of commuter students is worthy of further attention. Further exploration could identify specific barriers to accessing support services experienced by commuter students, such as requiring support out-of-hours. 


\section{References}

Abrams, H. G. and Jernigan, L. P. (1984) 'Academic support services and the success of high-risk college students', American Educational Research Journal, 21, pp. 261274.

Asher, A. D. and Miller, S. (2011) So you want to do anthropology in your library? Or a practical guide to ethnographic research in academic libraries. Available at: http://www.erialproject.org/wp-content/uploads/2011/03/Toolkit-3.22.11.pdf (Accessed: 20 September 2019).

Beisler, M. and Medaille, A. (2016) 'How do students get help with research assignments? Using drawings to understand students' help seeking behavior', The Journal of Academic Librarianship, 42, pp. 390-400.

Collins, E. and Stone, G. (2014) 'Understanding patterns of library use among undergraduate students from different disciplines', Evidence Based Library and Information Practice, 9, pp. 51-67.

Crosling, G., Heagney, M. and Thomas, L. (2009) 'Improving student retention in higher education: improving teaching and learning', Australian Universities Review, 51, pp. 9-18.

Dodgson, R. and Bolam, H. (2002) Student retention, support and widening participation in the north east of England. Available at:

https://www.researchgate.net/publication/252068942 . (Accessed: 20 September 2019).

Donnelly, M. and Gamsu, S. (2018), Home and away: social, ethnic and spatial inequalities in student mobility. Available at; https://www.suttontrust.com/wpcontent/uploads/2018/02/Home_and_away_FINAL.pdf (Accessed: 20 September 2019). 
Goldingay, S., Hitch, D., Ryan, J., Farrugia, D., Hosken, N., Lamaro, G., Nihill, C. and Macfarlane, S. (2014), ' "The university didn't actually tell us this is what you have to do": social inclusion through embedding of academic skills in first year professional courses', The International Journal of the First Year in Higher Education, 5, pp. 4353.

Jensen, K., Ramsden, B., Haigh, J. and Sharman, A. (2019), 'Using ethnographic methods to explore how international business students approach their academic assignments and their experiences of the spaces they use for studying', Evidence Based Library and Information Practice, 14, pp. 92-107.

Jiao, Q. G., Onwuegbuzie, A. J. and Lichtenstein, A. A. (1996), 'Library anxiety: characteristics of 'at-risk' college students', Library \& Information Science Research, 18, pp. 151-163.

Jones, R. (2008), Student retention and success: a synthesis of research. Higher Education Academy. Available at: https://www.advance-he.ac.uk/knowledgehub/student-retention-and-success-synthesis-research (Accessed: 20 September 2019).

Karabenick, S. A. and Knapp, J. R. (1991), 'Relationship of academic help seeking to the use of learning strategies and other instrumental achievement behavior in college students', Journal of Educational Psychology, 83, pp. 221-230.

Mcpherson, M. A. (2015), 'Library anxiety among university students: a survey' IFLA Journal, 41, pp. 317-325.

Mezick, E. M. (2015), 'Relationship of library assessment to student retention', The Journal of Academic Librarianship, 41, pp. 31-36.

Priestner, A. and Borg, M. (2016), 'Uncovering complexity and detail: the UX proposition', in Priestner, A. and Borg, M. (eds.) User Experience in libraries: applying ethnography and human-centred design. Abingdon: Routledge, pp. 1-8. 
Ramsden, B. (2016), 'Ethnographic methods in academic libraries: a review', New Review of Academic Librarianship, 22, pp. 355-369.

Soria, K. M., Fransen, J. and Nackerud, S. (2013) 'Library use and undergraduate student outcomes: new evidence for students' retention and academic success', Portal: Libraries and the Academy, 13, pp. 147-164.

Stone, G. and Ramsden, B. (2013), 'Library Impact Data Project: looking for the link between library usage and student attainment', College \& Research Libraries, 74, pp. 546-559.

Thomas, L. and Jones, R. (2017), 'Student engagement in the context of commuter students'. The Student Engagement Partnership. Available at: https://www.lizthomasassociates.co.uk/projects/2018/Commuter\%20student\%20en gagement.pdf (Accessed: 20 September 2019).

University of Huddersfield (2016), University of Huddersfield TEF provider submission. London: Office for Students. Available at: https://apps.officeforstudents.org.uk/TEFoutcomes/docs/submissions/Submission 1 0007148.pdf (Accessed: 20 September 2019).

Wernersbach, B. M., Crowley, S. L., Bates, S. C. and Rosenthal, C. (2014), 'Study skills course impact on academic self-efficacy', Journal of Developmental Education, 37, pp. 14-33.

Wingate, U. (2006), Doing away with 'study skills', Teaching in Higher Education, 11, pp. 457-469.

\section{Author details}

Laura Woods is Subject Librarian for the School of Computing and Engineering at the University of Huddersfield. 
Alison Sharman is Academic Librarian at the University of Huddersfield, with responsibility for the School of Computing and Engineering and the Business School.

Richard Dockery is Student Adviser in the School of Computing and Engineering at the University of Huddersfield. 